\title{
Editor's Note: Proficiency and Achievement: What Is the Difference and Why Should We
}

Care?

Elizabeth Gould

Over the last year or so, there has been quite a bit of activity on TESOL interest section discussion boards about the difference between proficiency and achievement and how these two concepts affect assessment practices in intensive English programs. The renewed interest first came to my attention last February after completing the AEC's 5-Year Review for CEA. One of CEA's standards requires students to be moved through a program of study "using instruments that appropriately assess the achievement of student learning outcomes for courses taken within the curriculum” (CEA Accreditation Manual, p. 41). This standard puts CEA squarely on the side of progressing students through a program on the basis of achievement while the AEC currently progresses students through our program mostly on the basis of proficiency.

This divergence prompted the necessity for a look at current literature related to this topic and so Mark Algren asked me to come up with some research questions that we could investigate over the course of a semester. The goal of this research was to give us a better understanding of what the literature says on this topic and to help guide our discussions as we begin to review, revise and develop our curriculum and assessment practices. Parul Sood and Jennifer Hornbaker were given these two heady research questions:

- Hornbaker: What is the relationship between language proficiency and student readiness to enter a program of study?

- Sood: What is the relationship between proficiency and achievement and what are the advantages and disadvantages of each as predictors of student readiness to enter their program of study?

In this Special Issue of ILI, you will read the results of Sood's and Hornbaker's semester-long efforts. Their reviews of the literature succinctly summarize key points in the research and clearly point out issues involved in measuring proficiency and tying proficiency to academic success. In this issue, Marcellino Berardo also attempts to characterize what is meant by "proficient enough" to achieve academic success.

To be clear, this issue of ILI in no way represents an official AEC position on proficiency versus achievement, nor does it indicate any shift in policy. Rather, these articles are meant to inform our discussion as we review our current curriculum and assessment practices. I hope you enjoy learning about this topic as much as I did! 